\title{
1 de julio en el Somme (1916): Errores y logros del ejército británico en el peor día de su historia militar
}

\author{
José RODRÍGUEZ TERCEÑO \\ Universidad Complutense de Madrid \\ josechavalet@gmail.com
}

Recibido: 15 de julio de 2013

Aceptado: 12 de septiembre de 2013

\begin{abstract}
Resumen
1916 supuso el año de estabilización en todos los frentes de la Gran Guerra. Tras las masacres en los campos de batalla -tierra y mar principalmente- las opciones para alcanzar una resolución del conflicto por medio de las actuaciones bélicas resolutivas se redujeron al máximo. De los horrores de la guerra, el primer día de la batalla del Somme pasará a la historia por ser el día más sangriento en la historia del ejército británico. Apremiados por el desangre francés, presionados al máximo por los aliados y empleando tácticas militares erróneas, miles de jóvenes británicos fueron llevados a una muerte segura en los hasta entonces floreados campos del valle del río Somme.
\end{abstract}

Palabras clave: Somme; Haig; Joffre; trincheras; artillería.

\section{July 1 in the Somme (1916): Errors and achievements of the British Army in the worst day of his military history.}

\begin{abstract}
1916 marked the year of stabilization on all fronts of the Great War. After the massacres in the fields of land and sea battle, mainly, the options to achieve a resolution of the conflict through adjudicative proceedings was minimized. From the horrors of war, the first day of the battle of the Somme will go down in history as the bloodiest day in British military history. Pressed by the French bleed, full pressed by allies and employing military tactics wrong, thousands of young Britons were taken to a certain death in the hitherto flowered files Somme River.
\end{abstract}

Key words: Somme; Haig; Joffre; trenches; artillery.

\section{Referencia normalizada:}

Rodríguez Terceño, J. (2013). 1 de julio en el Somme (1916): Errores y logros del ejército británico en el peor día de su historia militar. Historia y Comunicación Social. Vol. 18, págs. 109-123.

Sumario: 1. Introducción. 2. La gran ofensiva aliada. 3. 1 de julio de 1916. 4. Conclusiones. 5. Bibliografía. 


\section{Introducción}

Cuando la primera navidad de la Gran Guerra no trajo consigo el final de la contienda como muchos de sus combatientes esperaban, el desgaste pasó a ser el principal protagonista del conflicto. La guerra de movimientos agonizaba y dejaba paso a una guerra de trincheras que habría de escribir su lugar en la historia con la sangre de los millones de jóvenes que fueron enviados al frente. Durante 1915, los aliados prepararon la que iba a ser la gran ofensiva que rompería definitivamente las líneas alemanas, perfectamente asentados en territorio galo; pero el ataque continuado de éstos sobre el fuerte de Verdún dio al traste con todos los planes. El sitio de Verdún, que tenía por finalidad sangrar al ejército francés, algo que consiguió con creces, no tenía ningún valor estratégico para los germanos, más allá de desgastar las fuerzas enemigas, sabedores de que se dejarían hasta la última gota de sangre para no perder la ciudad-fortaleza que era para ellos un símbolo de valor y orgullo patrio. Erich Von Falkenhayn sabía que la batalla decidiría la supervivencia de Francia, a quien consideraba la espada en el frente del ejército británico, y que si los galos eran sometidos, a éstos les seguiría Rusia -siempre tuvieron en mente que, a pesar de la necesidad de derrotar a los rusos en el frente oriental, la contienda se decidiría en el frente occidental- y Gran Bretaña (quien, aislada, no tendría más opción que acordar los términos de la paz). La defensa liderada por Philippe Pétain acabaría con la carrera militar de Falkenhayn en el frente occidental y obligaría a los aliados a reconsiderar sus movimientos para, a un mismo tiempo, aliviar la presión a la que estaba sometido el exangüe ejército francés en Verdún y penetrar y romper definitivamente las líneas enemigas, recuperando la guerra de movimientos que daría fin al conflicto. De esta forma, los planes estudiados durante el segundo año de la guerra ${ }^{1}$ que debía ponerse en práctica una vez entrado el año 1916, tuvieron que ser modificados conforme avanzaban los primeros meses y con ellos la batalla de Verdún. Este fue el origen de la batalla del Somme, uno de los capítulos más costosos, en lo que a vidas humanas se refiere, de la historia militar, pero muy especialmente de la historia militar británica, quienes se vieron obligados, debido a las bajas francesas, a aportar el grueso de infantería que lucharía en el valle del rio Somme. La batalla, que se prolongaría durante más de cuatro meses, no estuvo perfectamente planificada, condenando a toda una generación de jóvenes (británicos, alemanes y franceses principalmente) siendo hoy recordada, sobre todo, por su primer día de ofensiva, uno de los días más sangrientos que tuvieron lugar durante la Gran Guerra.

Considerando la necesidad epistemológica sustentada sobre la analítica de fuentes para describir el estatus de partida del objeto de nuestro estudio, el proceso inductivo-deductivo, integrado por el desarrollo del análisis y la síntesis que descompone un fenómeno en los principales elementos que lo integran para analizar, valorar y conocer sus particularidades, así como su interrelación como un todo, se erige como el método más adecuado para poder avanzar en los conocimientos y saberes humanísticos como el que nos ocupa. Recurrir al estudio de todas y cada una (inclusive a las principales nada más) de las fuentes existentes sobre la Primera Guerra Mundial, incluso cuando se trata de un periodo muy concreto de cuatro meses y medio (dura- 
ción de la batalla del Somme) o solamente de su primer día de hostilidades, es una tarea que, conforme a los objetivos del presente estudio, se nos hace inasible, pues requeriría de un mayor tiempo y esfuerzo que solo podemos traducir en términos de longevidad equiparables a la vida media de una persona. Es por ello que hemos recurrido a las principales fuentes bibliográficas sobre el acontecimiento en cuestión, algunas fuentes primarias -siempre que se ha podido- y otras fuentes secundarias (que permiten el conocimiento de las primeras) de rigurosidad probada.

La batalla del Somme es uno de los acontecimientos que mayor literatura ha generado a su alrededor, más allá de la historia oficial publicada (1932 y 1938) y de los escritos de las diferentes divisiones, batallones, regimientos, pelotones, etcétera, que fueron protagonistas de la misma. Se ha escrito sobre todos los aspectos, que no son pocos, que tuvieron lugar durante los casi cinco meses que duró el conflicto (el reclutamiento, el papel de la artillería, la irrupción del carro de combate -tanque-, los soldados del frente, y un largo etcétera). En algunos casos, esta abundancia de escritos es perjudicial para la labor investigadora pues las más de las veces "nos vemos inundados por una avalancha de publicaciones americanas y británicas (especialmente inglesas) que con menos melindres existenciales, más sentido de la oportunidad y pragmatismo histórico ofrecen sus gloriosos (o no) hechos de armas, siempre magnificados y muchas veces hinchados, cuando no deliberadamente deformados" (Sancho Gómez, 2003: 77). Nuestra intención es centrarnos, una vez contextualizada la batalla, en los acontecimientos del primer día (casi sería más correcto decir medio día) y en los errores y logros que trajo consigo para el ejército británico, principal protagonista, junto a los alemanes, de la contienda -el mariscal Joseph Joffre la denominó, y con razón, "la batalla inglesa"-.

\section{La gran ofensiva aliada}

Cuando dio comienzo el año 1916, el frente occidental de la Gran Guerra se encontraba en un punto muerto. Desde el mar del Norte hasta la frontera suiza no se producían avances significativos, ningún movimiento importante; los dos bandos estaban más atrincherados que antes, más establecidos en sus respectivas trincheras que nunca. Hacía ya tiempo que la esperanza de una rápida resolución de "la guerra destinada a acabar con todas las guerras" se había perdido. Pronto comenzó a extenderse un sentimiento común, la impresión de una próxima ofensiva aliada, una operación franco-británica que los mandos aliados querían desarrollar en el sector de Noyon, una ofensiva cuya principal finalidad era romper el frente alemán, favoreciendo la profundización en sus líneas. Este ataque coincidiría con las acometidas rusa e italiana, constituyendo la que sería, sin lugar a dudas, la gran ofensiva aliada.

El 6 de octubre de 1915, en el cuartel general militar francés en Chantilly, tuvo lugar un encuentro presidido por el general Joseph Joffre (jefe supremo de las fuerzas francesas), el comandante en jefe de la Fuerza Expedicionaria Británica, John French, $\mathrm{y}$ los generales del alto mando ruso e italiano. Juntos planificaron una ofensiva a gran 
escala, simultánea, en todos los frentes de la contienda, evitando de esta forma que los recursos de Alemania y Austria-Hungría se concentrasen en una única zona de conflicto. Rusia atacaría al norte a los alemanes y al sur a los austrohúngaros, Italia arremetería nuevamente a través del rio Isonzo para tratar de penetrar en Austría, y la alianza franco-británica realizaría una ofensiva en el valle que dibujaban los márgenes del rio Somme, en la región francesa de Picardía. Según el plan previsto, la gran ofensiva de la Entente debía estar lista para la primavera del año siguiente. En noviembre de ese mismo año, Douglas Haig sucedería a French como comandante de la Fuerza Expedicionaria Británica ${ }^{2}$, un firme partidario de desgastar al adversario y minar sus recursos hasta poder lanzar el ataque decisivo que rompiera las líneas enemigas. Una vez estuviera fatigado y sin reservas, una masa de tropas avanzaría sobre las líneas enemigas penetrando con facilidad en ellas hasta lograr la victoria. Haig, que contó siempre con el apoyo del secretario de Estado para la guerra, el capitán general conde Horatio Herbert Kitchener de Jartum, pronosticó para mayo o junio la fecha más temprana para tener preparada la ofensiva británica.

Independientemente del avance alemán sobre Verdún, uno de los principales defectos del bando aliado que evidenciaría la batalla del Somme (entre otras) fue sin lugar a dudas la ausencia de un mando único. Joffre, el alto mando francés que más presión ejercía sobre Haig para adelantar la intervención en Picardía tras el desangre de su ejército, no era quien acaudillaba a los aliados en territorio francés, pues los británicos mantuvieron desde el comienzo de la guerra la independencia de mando - una cuestión bastante acusada, por otro lado, en todas las alianzas bélicas-. "La zona de operaciones elegida fue más un producto del compromiso que de la conveniencia táctica, pues no era la adecuada para la ofensiva británica ni para la francesa. A los primeros les interesaba atacar la zona del litoral, y a los franceses les convenía hacerlo entre el Mosa y el Mosela para amenazar las comunicaciones alemanas con el Rin. No pudiendo conciliar ambas conveniencias, y dada la necesidad de empeñar las dos fuerzas, se optó por atacar por la zona donde ambas se hallaban en contacto, es decir, por donde se encontraban ya desplegadas las tropas británicas y francesas, $o$ lo que es lo mismo, por ambos márgenes del río Somme" (Quero Rodiles, 2009: 315).

El ataque alemán liderado por Falkenhayn e iniciado el 21 de febrero de 1916 sobre Verdún constituiría el primero de los muchos pasos que cambiarían por completo la planificación de la ofensiva aliada y la intervención del grueso del ejército británico en Francia. Cuanto más se intensificó el ataque sobre Verdún y mayores fueron las pérdidas y el desgaste del ejército galo, mayor era la presión a la que fue sometido el alto mando británico, y especialmente la figura de Douglas Haig, para que adelantara sus movimientos en el Somme. Esa presión para iniciar la acometida estaba igualmente amenazada por la sombra de una desigual negociación de un hipotético tratado de paz con los alemanes, como bien advirtieron desde la cúpula política británica, porque el punto muerto, el atrincheramiento y la falta de avances estaban agotando sus recursos y sin ellos estarían perdidos, es decir, no tendrían nada con que negociar. Pese a todo, también se elevaron voces de prudencia ante la precipitación de 
la ofensiva en territorio francés ${ }^{3}$, más partidarias de aguardar hasta que fueran lo suficientemente fuertes.

Pese a que la fortaleza francesa resistió, los líderes políticos y militares anglo-franceses, reunidos en marzo de 1916, apremiaron la intervención británica ante las innumerables pérdidas (no solo humanas) que se estaba cobrando la batalla. Pese a todo, Haig advirtió a Kitchener que con lo único que contaba era con divisiones no entrenadas para el campo y no con un ejército preparado, en otras palabras, los soldados enviados al frente para el ataque en el Somme eran inexpertos (nunca habían entrado en combate), lo cual no garantizaba el éxito de la contienda. Muchos de estos soldados inexpertos fueron reclutados voluntariamente en las campañas de alistamiento ideadas por Kitchener (a este Nuevo Ejército se le conoce popularmente como el ejército de Kitchener) y el general Henry Rawlinson (protagonista también de la batalla del Somme). El secretario de Estado para la guerra siempre previó una larga duración del conflicto bélico y la necesidad, por consiguiente, de un numeroso ejército con el que luchar. Rawlinson, por su parte, sugirió que los hombres estarían más dispuestos a alistarse si podían servir junto a aquellos a quienes mejor conocían. Nacerían de esta forma los conocidos batallones de amigos, compuestos por colegas de barrios, trabajadores de una misma empresa o industria, miembros de equipos de fútbol, de escuelas, de clubes, etcétera. Fue un gran "esfuerzo a nivel nacional. Kitchener animó a las ciudades y pueblos de toda Gran Bretaña a que organizasen campañas de reclutamiento" que consiguieron que en los dos primeros meses tras la declaración de guerra, "más de cincuenta ciudades y pueblos de toda Gran Bretaña formaran batallones de camaradas" (Gilbert, 2009: 21). La idea inicial de Kitchener era que estos hombres fueran convenientemente entrenados y mejor dirigidos en el campo de batalla, por lo que sus entrenamientos no estarían del todo completados hasta los primeros meses de 1916, según se estimaba, entrando en conflicto, para entonces, como una única entidad. El bautismo de fuego de estos pobres malditos fue la batalla del Somme y muchos no vivieron para recordarlo.

Con el punto muerto al que se llegó en 1915, la vida en las trincheras pasó a ser todo lo tranquila que puede ser en un conflicto armado internacional. Los alemanes, instalados en territorio francés desde finales de 1914 (y más preocupados que sus enemigos en la preparación de sus defensas), se dedicaron a reforzar sus líneas de trincheras, construyendo profundos refugios subterráneos con fortificaciones de hormigón; unas construcciones que los protegerían durante los intensos ataques de artillería que el ejército británico lanzaría en los días previos al ataque.

El desarrollo de la batalla de Verdún estaba provocando un efecto de peligro inmediato en el panorama general de la guerra y en las fuerzas británicas que se estaban preparando para la gran ofensiva. Las cifras de las divisiones que los franceses podrían emplear en el avance del Somme se veían reducidas con el paso de los días y la continuación de la masacre de Verdún. La organización de la batalla no podía ser más imprecisa. La inestabilidad francesa era contrarrestada por una fuerte presión ejercida sobre Douglas Haig; Joffre no quería que el ataque se postergara más allá del 1 de julio, aunque ello supusiera no coordinar las diferentes zonas de asalto siempre 
que el resultado fuera desplazar a los alemanes lejos de Verdún, reduciendo la presión sobre los galos. Pero, tener bien adiestrado al Nuevo Ejército y bien planificados los avances sobre una línea de trincheras de más de treinta kilómetros, era una ardua tarea que requería de todo el tiempo posible. Los británicos atacarían con su grueso en el norte, mientras que las pocas divisiones proporcionadas por los franceses lo harían en el sur. Haig confiaba en sus dotes de mando, en la estrategia planificada y en la capacidad (y número) de sus tropas, quienes, pese a la inexperiencia, estaban henchidos de moral victoriosa y patriotismo (algo de elogiar tras el resultado del primer día de batalla, porque pese a las innumerables bajas, el ataque sobre las líneas alemanas atravesando tierra de nadie no cesó ni un momento).

El Mariscal de Campo siempre tuvo claro que su ejército sería mucho más fuerte si el avance sobre el Somme se retrasaba hasta el 15 de agosto, pero las consecuencias de no ofrecer un apoyo rápido a los franceses podrían resultar desastrosas. Como él mismo se encargaría de señalar en uno de sus despachos: "A pesar de que el 15 de agosto era la fecha más favorable para que el ejército británico entrase en acción, en vista de lo que le había dicho acerca de la desafortunada situación del ejército francés, yo estaba dispuesto a iniciar las operaciones en torno al 1 de julio". "La reticencia de Haig a iniciar la ofensiva antes del 15 de agosto fue absolutamente ignorada por el jefe supremo francés. El gobierno británico estaba comprometido y resuelto a ayudar a Francia a escapar del peligro de una derrota en Verdún, o en cualquier otro lugar. La derrota de Francia supondría un gran peligro para Gran Bretaña. Haig no tenía más alternativa que la de adherirse a las exigencias de los franceses" (Gilbert, 2009: 50).

La acumulación de hombres, municiones, cañones y demás ya tenía fecha límite, además del desarrollo táctico que tan simple visualizó Haig. Tras el constante y destructor fuego de artillería, las tropas del ejército de Kitchener -entre otras ${ }^{4}$ - saltarían las trincheras para atravesar tierra de nadie hasta alcanzar las líneas alemanas, penetrando en ellas de forma sucesiva (y con facilidad) hasta ir liberando pueblos y aldeas, dejando vía libre a la tan amada caballería del Mariscal de Campo, para que ésta entrara profundamente en la Francia ocupada ${ }^{5}$. Pero este diseño táctico no era compartido por todo el mundo. El general Rawlinson, quien estaría al mando del $4^{\circ}$ Ejército en lo que sería el ataque principal del Somme, no veía exitosa la planificación de Haig, no, al menos, veía tan factible la invasión, captura y victoria aliada. Tampoco el general Hunter-Weston, combatiente en Gallípoli, estaba seguro del plan del Mariscal. Pero Haig ignoró estas advertencias, convencido del éxito de su plan y del cambio de rumbo que desde entonces tomaría la guerra.

La zona de Picardía recorrida por el río Somme contaba con una gran cantidad de puebles pequeños en manos alemanas, bien fortificados. La zona al norte del Somme era muy accidentada, más fácil para el movimiento de las tropas desplegadas, mientras que la zona sur, con un terrero más suave, ofrecía un buen escenario para el fuego (ametralladoras especialmente) pero no así para las soldados. Por lo tanto, el norte estaba formado por un terreno de colinas largas y onduladas y el sur por una zona de llanura con muy pocas irregularidades. El norte (entre el río Ancre y Comles) era el escenario donde operarían las tropas británicas; el centro (entre Combles y el río 
Tortille) lo sería para la coalición franco-británica; y el sur (por debajo del Somme) sería el espacio de despliegue de los franceses.

Otra de las claves tácticas eran los sistemas de carreteras de la zona, especialmente la carretera principal que unía Amiens, Albert y Cambrai (la frontera de Bélgica por decirlo de otra forma), y el triángulo formado por la carretera que unía Albert, Bapaume y Peronne.

La mayoría de estas zonas, así como los pueblos y aldeas, y las pequeñas alturas, estaban en manos de los alemanes, "con lo que a las ventajas del dominio que le proporcionaba su fortaleza natural, se añadía una estupenda organización defensiva" (Quero Rodiles, 2009: 314) como ya hemos señalado. Los pueblos y aldeas, por pequeños que fuesen, se convirtieron en fortalezas, se construyeron reductos (Schwabenm, Stuff, Leipzig, entre otros), se fortificaron los bosques colindantes, y rodearon todas las posiciones con varias líneas de alambrada, y, como ya se mencionara antes, se construyeron refugios profundos, contando con algunas comodidades como muebles, camas, luz eléctrica y agua corriente. Como, pese a la necesidad de adelantar la ofensiva, nunca hubo un factor sorpresa determinante (la acumulación de hombres, armas y municiones fue observada por los alemanes), las tropas enemigas tuvieron tiempo más que suficiente para preparar su defensa, perfeccionando y completando su organización, "aumentando la profundidad de los refugios, estableciendo posiciones de flanqueo, de bloqueo y alternativas, tendiendo alambradas, e incrementando y mejorando los asentamientos de las armas, especialmente de las ametralladoras" 6 en zonas elevadas desde las que observaron, el primer día de lucha, desplazarse a los soldados británicos y franceses antes de abrir fuego sobre ellos.

A lo largo de la línea del frente que unía, de norte a sur, Serre, Thiepval, Fricourt, Maricourt, Frize, Fay y Chilly, se estableció una zona de ruptura entre las ciudades de Thiepval y Littons, de una extensión de aproximadamente treinta kilómetros. El esfuerzo principal iniciado el uno de julio de 1916 correría a cargo del grupo de ejércitos del norte, británico aunque con participación (muy escasa) francesa, liderado por el general $\mathrm{Haig}^{7}$ y los generales Allenby ( $3^{\text {er }}$ ejército), Cough $\left(5^{\circ}\right.$ ejército) y Rawlinson ( $4^{\circ}$ ejército). Un esfuerzo secundario tendría lugar en el sur, participando los ejércitos al mando del general Foch ${ }^{8}$ y los generales Fayolle ( $6^{\circ}$ ejército) y Micheler ( $10^{\circ}$ ejército).

Por la parte alemana, la defensa estaría liderada por jefe del Estado Mayor General, el general Falkenhayn -quien, tras el fracaso de Verdún y la incapacidad para poner fin a la batalla del Somme fue sustituido por el general Paul Von Hindenburgy el general Von Below ( $2^{\circ}$ ejército) y los mandos de las agrupaciones en las que el segundo ejército se dividía, general Von Stein (agrupación Stein, tres divisiones al norte del río Somme), general Von Gosler (agrupación Gosler, dos divisiones al norte) y el general Von Quast (agrupación Quast, dos divisiones al sur del río) ${ }^{9}$.

A medida que se acercaba el 1 de julio, la acumulación de hombres, municione ${ }^{10} \mathrm{y}$ provisiones era cada vez mayor. El grueso británico era entonces un poderoso grupo, aunque algunos de sus soldados, los hombres del Nuevo Ejército, jamás hubieran 
entrado en combate. Pese a su inexperiencia, estaban llenos de valor, entrega y sacrificio. Además, como bien ha hecho constar Quero Rodiles, "procedieron a mejorar las carreteras y caminos, a construir nuevas vías férreas, abrigos enterrados, miles de kilómetros de trincheras y una multitud de tuberías de agua” (2009: 318).

Todo estaba listo para la gran ofensiva, cuya finalidad principal no era, en ese momento, romper el frente alemán para profundizar (aunque fuera ésta una de las intenciones perseguidas por el ejército británico) sino desgastar al enemigo para agotar sus fuerzas y recursos, obligándoles a recuperar parte de sus contingentes, reduciendo la presión que Alemania estaba ejerciendo sobre Verdún. En otras palabras, la intención era colocar una fuerza militar considerable en la zona de comunicaciones alemana en la región del Somme. Pese a los esfuerzos llevados a cabo por británicos y franceses, el éxito fue, desde el comienzo, esquivo a las maniobras aliadas, pues ya desde un primer momento, antes incluso de haberse iniciado el asalto sobre las líneas alemanas, "llama la atención la divergencia inicial de ambos esfuerzos (movimientos hacia el nordeste y el este) en contra de la intención y del mandato del terreno" (Quero Rodiles, 2009: 314).

\section{1 de julio de 1916}

Una vez iniciado el asalto a Verdún, la planificación de la ofensiva aliada franco-británica en el Somme fue superada por las presiones de las circunstancias de guerra que entonces se vivieron. Pese a los esfuerzos del general Joffre por adelantar lo máximo posible el ataque, la batalla vio su puesta en ejecución retrasada varias veces por las dificultades planteadas por el mando británico, quienes, finalmente, cedieron a la presión gala, adelantando al 1 de julio de 1916 el ataque sobre líneas alemanas, pese a la consideración del general Haig de que no todos sus hombres estaban lo suficientemente preparados. Puede pensarse que la presión y la premura en su ejecución no es razón suficiente para que la ofensiva sobre el Somme -ideada desde el año anterior- fracasara en sus primeros movimientos ${ }^{11} \mathrm{y}$ tuviera como resultado el mayor número de pérdidas humanas que hasta entonces se había contabilizado la Gran Guerra. Pero, quién sabe si fue el destino quien así lo escribió, la ofensiva sobre el Somme comenzó a no ir del todo bien desde los días precedentes al primero de julio.

Douglas Haig y Ferdinand Foch acordaron poner en práctica la conocida como 'doctrina del Somme' para llevar a cabo la ofensiva franco-británica. Esta doctrina exigía un aplastante y continuado fuego de artillería sobre las líneas alemanas para destruir la mayor parte de sus defensas (alambradas, trincheras, puestos de vigilancia, puesto de ametralladoras, puestos de francotiradores, etcétera) como preparación para un posterior despliegue de tropas de ocupación sucesiva de los objetivos tácticos, posiciones y zonas dominantes del terreno. Era lo que hoy conocemos por un procedimiento de objetivos sucesivos, que rompería el frente alemán y permitiría una profundización de los soldados y la caballería. 
La doctrina y la batalla del Somme se concibieron para desarrollarse de forma rápida, pero la necesidad de desgastar a un enemigo que estaba desangrando al ejército francés, y el fracaso de las primeras incursiones, modificó el ritmo de las operaciones británicas sobre el terreno, hasta poder diferenciarse cuatro grandes fases en el desarrollo de la batalla ${ }^{12}$.

El general Rawlinson, mando encargado del escenario principal de la batalla, concretó el día 29 de junio para el inicio de las hostilidades (finalmente retrasado al día 1 de julio por las condiciones climatológicas adversas). En los días previos al ataque, entre cinco y ocho días antes, como preparación al avance de la infantería, se ordenó un intenso y continuado bombardeo sobre las líneas de defensa alemanas, solamente interrumpido cuando el clima no permitía su utilización. La fuerza de artillería empleada superaba cualquiera conocida hasta entonces, ocupando, además, un frente muy superior al previsto, pues no se quería descubrir la zona concreta de ruptura (recordemos que el frente superaba los treinta kilómetros). El mando británico estaba convencido que el único resultado posible de este bombardeo constante era la destrucción de las defensas alemanas, por lo que el avance, previsto para las 07:30 horas de la mañana del primero de julio, iba a ser lento, casi un paseo militar hasta las posiciones enemigas, que se creían destruidas y abandonadas. Pero la realidad es que los alemanes habían aguantado en sus posiciones (pese a los destrozos ocasionados por el bombardeo) y respondieron al avance británico con fuego mortal de ametralladoras (que llegaron a destruir batallones enteros) ante el que los soldados expuestos no pudieron hacer nada.

Durante los días previos, doscientos cañones pesados y aproximadamente mil ochocientos ligeros (de 18 libras destinados al disparo de metralla) bombardearon intensamente las líneas alemanas con la intención de destruir y conquistar, para que la infantería ocupara trincheras, hiciera prisioneros, enterrara a sus muertos y siguiera avanzando. Pero la realidad fue bien diferente. Muchos de los proyectiles dispuestos para el fuego estaban preparados por trabajadores sin experiencia en munición de artillería (quienes verdaderamente sabían ejercían como voluntarios hacía y o bien estaban en las trincheras o bien estaban muertos). Por ello, aproximadamente un tercio de los proyectiles lanzados no llegaron a explotar, y de los que sí lo hicieron, muchos tuvieron un efecto escaso de destrucción. Lo que sí tuvo efecto sobre el enemigo fue el enorme esfuerzo logístico necesario para la acumulación de proyectiles de artillería (no solo de municiones, también de hombres a la zona destinados), que no pasó desapercibido, lo que era una clara señal de una inminente ofensiva, ofreciendo un tiempo más que valioso a los alemanes para preparar mejor sus defensas. Además, el retraso en el inicio del ataque extendió más el bombardeo, lo que obligó a dosificar los proyectiles para que durasen hasta el inicio del avance, diluyendo el fuego de artillería y perjudicando el resultado final del castigo previo al uno de julio.

Los ánimos de los soldados británicos que esperaban con impaciencia el ataque se agitaron con el retumbar del fuego de artillería, que llego a alcanzar, en algunos momentos, un ritmo de 3.500 proyectiles por minuto (Gilbert, 2004: 346). Pero las patrullas de exploración que regresaron antes del inicio del ataque, así como la 
exploración desde el aire que llevaron a cabo algunas aeronaves, y los interrogatorios a soldados alemanes hechos prisioneros horas antes del combate, ofrecían noticias alarmantes. No sólo no se había conseguido destruir las primeras líneas de defensa alemanas, sino que además la alambrada (la mayor parte por mejor decir) seguía intacta. El fuego de artillería solo había conseguido destrozar el terreno que la infantería debía cruzar aquella mañana de junio, perjudicando su avance y favoreciendo su posición como blancos para las ametralladoras alemanas. Pero los mandos británicos, seguros de la victoria y del éxito del bombardeo, ignoraron los informes, en algunos casos, desestimándolos como 'pánico anterior a la batalla'. Por ello, el avance de los soldados aquel 1 de julio fue tan lento.

En la planificación del ataque previo a la batalla del Somme, conjuntamente al fuego de artillería también se proyectó la colocación de minas subterráneas para hacerlas explotar en los minutos previos a las 07:30 de la mañana. Durante el mes de junio, mineros de la zona de Yorkshire y Escocia cavaron túneles bajo tierra de nadie y las defensas alemanas ${ }^{13}$ (si no debajo de éstas, muy cerca de las mismas, recordemos que algunas defensas alemanas eran muy profundas). El objetivo era colocar enormes minas compuestas de amonal (explosivo mezclado con nitrato de amonio y aluminio en polvo) para que hicieran explosión minutos antes del ataque principal. El trabajo era lento y delicado. Los mineros trabajaban en pequeño túneles con el peligro de derrumbamiento pendiendo sobre sus cabezas, así como de alertar al enemigo con su trabajo. Las maniobras con el pico eran muy lentas; la punta de la herramienta se cubría con tela y los escombros se recogían cuidadosamente para ir pasado de un hombre a otro hasta acumularse en sacos que luego serían utilizados para bloquear los túneles una vez estuvieran colocadas las minas.

Con las explosiones se pretendía sorprender al enemigo y procurar algunos puestos elevados como consecuencia de los levantamientos de tierra, roca y polvo. Pero la sincronización no fue buena. Los minutos previos a la maniobra principal el fuego de artillería aumentó su intensidad, pero diez minutos antes de las 07:30 hizo explosión la primera de las minas, alertando de las siguientes explosiones, que se sucedieron un par de minutos antes del ataque. La mina de Hawthorn explotó antes que ninguna otra, levantando un enorme muro de tierra y roca ${ }^{14}$. Fue seguida por el resto de los explosivos; la mina más grande, cerca del punto de apoyo del reducto de Schwaben originó el cráter de Lochnagar de más de noventa metros de diámetro y veintisiete de profundidad y consiguió reducir a escombros nueve refugios alemanes. Las detonaciones pillaron desprevenido al enemigo y causó bastantes bajas en las filas alemanas, pero dificultaron también el avance de los primeros soldados. Éstos tenían orden de avanzar sobre el terreno, no de correr de un puesto cubierto a otro, por lo que tardaron en alcanzar los márgenes de algunas hendiduras. Además, el fuego de artillería disminuyó para evitar alcanzar a sus tropas. Todo ello dio tiempo a que los alemanes se reorganizaran e instalaran puestos de defensa con ametralladoras en los cráteres que las minas británicas habían creado. La irregularidad del terreno y el polvo y la tierra esparcidos por el aire dificultó el avance de los soldados aliados. La sorpresa 
que se esperaba descompusiera las defensas alemanas, pese a causar bajas entre éstas, entorpeció la ofensiva británica.

Cuando los soldados británicos saltaron la trinchera aquella mañana de julio y comenzaron a avanzar sobre tierra de nadie, la gran mayoría como tropas de consolidación en vez de tropas de infiltración o penetración, portaban con ellos casi treinta kilos de peso. Rifle con bayoneta, cartuchos de munición, granadas Mills, chubasquero, bengalas, sacos de arena, un casco de acero, dos cascos anti-gas, gafas protectoras, equipamiento de primeros auxilios, una lona impermeable, cantimplora, un macuto (plato para comer, raciones de comida, toalla, kit de afeitado, calcetines, una libreta de mensajes); además, algunos soldados portaban con ellos palas, picos, hilo de alambre, ametralladoras, munición extra para éstas, estacas para soportes de trincheras, puentes y escaleras de trincheras, cizallas, torpedos Bangalore e incluso latas de pintura para identificar las unidades capturadas. Por si el peso no fuera poco, cada hombre llevaba a su espalda un triángulo de hojalata para identificar su posición a su propia artillería, pero el destello que éstos provocaban aquella mañana de julio también posicionó a tiro a los británicos con respecto a los hombres de las ametralladoras alemanas.

El alto mando no estaba muy seguro de que los hombres sin experiencia del nuevo ejército pudieran llevar a cabo tácticas de alto nivel, acciones de combate que el ejército regular llevaba casi dos años practicando en la contienda. Por ello, los generales al mando ordenaron a sus hombres maniobras que estuvieran a su alcance, y éstos avanzaron caminando sobre tierra de nadie y no corriendo de un puesto cubierto a otro. La confianza que se tenía en la destrucción de las líneas alemanas por parte del fuego de artillería era absoluta, tanto es así que el ataque se inició en plano día, con una perfecta visibilidad, con un equipo excesivamente pesado para un avance rápido y a un ritmo peligrosamente lento (de unos cien metros por minutos). El bombardeo y las explosiones de las minas dificultaron el avance, "el desastre para las fuerzas británicas no pudo ser más fuerte, sangriento y lastimoso" (Quero Rodiles, 2009: 321).

Esta incompetencia de los oficiales británicos no paso desapercibida a los altos mandos alemanes, quienes acuñaron la expresión 'leones por corderos' para designar a estos oficiales que desde la seguridad de la retaguardia sacrificaban a sus jóvenes soldados. "La mayor parte de los expertos están de acuerdo que esa expresión tiene su origen en la batalla del Somme [...] Mientras algunos historiadores militares acreditan como autor a un infante anónimo, otros arguyen que la fuente no es otro que el general Max Von Gallwitz, el Comandante Supremo de las Fuerzas Alemanas" (Cabezuelo Lorenzo, 2009: 17).

Las fuerzas alemanas, con importantes bajas, destruyeron batallones enteros del ejército británico, pero el ataque no vacilo en ningún momento, el valor que portaban los soldados no se quebró pese al caos que reinaba en la zona de combate. Al mediodía, aproximadamente unas 50.000 bajas se contaban en el ejército británico, entre muertos y heridos, algo que hubiera hecho imposible reiterar el ataque, pero ciertos problemas de comunicación ocasionaron que muchos altos mandos no supieran cuál 
era el desarrollo de la batalla hasta que no fue demasiado tarde. El general Haig tampoco estaba dispuesto a desistir de su intención de aprovechar la ocasión para derrotar definitivamente a los alemanes. Como consecuencia, "cambió el estilo y la dirección de su ofensiva, sustituyendo el ataque en fuerza en frente extenso, por un ataque frontal en frente estrecho, lento y constante, para producir un desgaste importante al enemigo" (Quero Rodiles, op. cit.: 321).

\section{Conclusiones}

Al acabar el día, 67.000 fueron las bajas en el ejército británico, de los cuales, la mayoría de los muertos y heridos lo fueron antes de las doce del mediodía. La tarde del uno de julio algunos ataques similares fracasaron nada más saltar la trinchera, pero otros ataques tuvieron mejor suerte. Finalizado el primero día de la batalla del Somme y pese a la masacre sufrida, se obtuvieron algunos avances. La $36^{\text {a }}$ división del Ulster atacó el reducto de Schwaben, en el centro del ataque principal (en la zona de Thiepval), capturando la posición y haciendo prisioneros a unos quinientos alemanes. La táctica seguida por estos hombres fue diferente, más cercana a las ideas del general Rawlinson, quien era partidario de aplicar lo que él denominaba 'morder y aguantar', es decir, atacar las trincheras alemanas y no progresar más, no atacar más allá de lo que cubría la artillería. La división avanzó por tierra de nadie mientras el fuego de artillería aún estaba en marcha, al llegar a las líneas alemanas el factor sorpresa fue determinante, el enemigo no tuvo tiempo de recuperarse y reorganizar sus defensas.

La $30^{\text {a }}$ división al sur se apoderó de Mountauban e incluso persiguió a los alemanes valle abajo. El $3^{\text {er }}$ ejército, cuya ofensiva sobre Gommencourt pretendía distraer

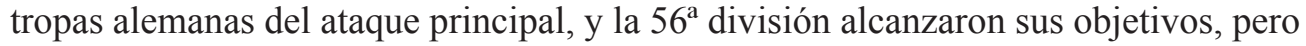
a un alto coste. En Mametz la $7^{\text {a }}$ división y la $18^{\mathrm{a}}$ división consiguieron también sus objetivos. Estos breves logros no pudieron tener continuidad debido a las numerosas bajas, debido al fracaso generalizado del primer día.

Durante la noche del uno de julio se pudo recibir cargamentos y suministros, así como asistir a los heridos que no pudieron ser evacuados de tierra de nadie. Algunos de estos hombres acabarían muriendo tras días agonizando cerca de las líneas alemanas sin posibilidad de poder ser asistidos o evacuados. La magnitud de la masacre de ese primer día no se comprendió en su totalidad en el cuartel general británico hasta el tres de julio. La esperanza de un éxito rotundo obtenido con la gran ofensiva desapareció y la coalición franco-británica y el ejército alemán se prepararon para una batalla de desgaste que habría de durar meses. No tendría fin hasta el que mal tiempo se hizo dueño del Somme en noviembre de ese mismo año. Más de cuatro meses de masacre. Puede decirse que aquel uno de julio de 1916 Gran Bretaña había perdido a su juventud como consecuencia de una mala planificación militar y el gran esfuerzo defensivo alemán. La historia popular ha culpado a Douglas Haig como máximo responsable, debido a su constante repetición de tácticas fallidas y la más 
que evidente falta de fe en las tropas inexpertas, pero no fue el único involucrado, el resto de sus oficiales también participaron en la planificación de la ofensiva.

Políticamente y estratégicamente la batalla del Somme no supuso ninguna ventaja territorial para los aliados ya que no pudieron penetrar más de diez kilómetros en las defensas alemanas, pero sí que inició el fracaso definitivo de los planes germanos para Francia. El Somme se convertiría en la tumba de barro del viejo ejército alemán, que después de los fracasos de 1916 (Verdún y Somme) no estaba dispuesto a involucrar a su ejército en otra batalla de desgaste similar. "La finalidad conseguida fue más producto del espíritu ofensivo aliado y de la reiteración de sus esfuerzos que del éxito de la maniobra; el elogio del valor, la intrepidez, los valores morales, la audacia y la impulsión fueron los factores determinantes de las tendencias tácticas"15.

Si algo puso de manifiesto el año 1916 fue la estabilización de todos los frentes de la contienda. El desgaste llegaría a su punto álgido y las pérdidas para ambos bandos serían irremplazables. El Somme acabaría en parte con las esperanzas alemanas, marcaría para siempre al general Haig como 'el carnicero' y supondría una de las batallas, si no la mayor, más sangrientas de la Gran Guerra. El 1 de julio pasará a la historia como el día más sangriento en la historia militar británica, pues en las tierras del Somme quedarían olvidados para siempre miles de jóvenes que empujados por el valor y el patriotismo fueron lanzados (caminando por tierra de nadie) a la peor de las muertes.

\section{Bibliografía}

ASTORRI, A.; SALVADORI, P. (2002). Atlas ilustrado de la Primera Guerra Mundial. Madrid: Susaeta.

BARTLETT, K. (ed.) (sin fecha). Somme. Londres: Oficina Pública de Registros, Archivos Nacionales.

BECKER, J. J. (2007). La Gran Guerra: la Primera Guerra Mundial. Barcelona: Davinci Continental.

BORLASTON, J. H. (1919). Despachos de Sir Douglas Haig (Diciembre 1915-Abril 1919). Londres: J. M. Dent.

CABEZUELO LORENZO, F. (2010). "El compromiso periodístico, político, militar y académico según Robert Redford". En: Vivat Academia, no 110, Madrid: Universidad Complutense, p. 1-20.

CUTTELL, B. (1997). One day on the Somme, 1st july 1916. Peterborough: GMA.

EDMONDS, J. E. (1932). Operaciones militares en Francia y Bélgica, 1916, Órdenes de Sir Douglas Haig en 1 de julio: Batalla del Somme. Londres: Museo Imperial de Guerra.

GILBERT, M. (2004). La Primera Guerra Mundial. Madrid: La Esfera de los Libros.

--- (2009). La batalla del Somme. La batalla más sangrienta de la primera guerra mundial. Barcelona: Ariel.

GRAVES, R. (1985). Adiós a todo eso. Barcelona: Edhasa. 
MIDDLEBROOK, M. (2003). The first day on the Somme. Barnsley: Leo Cooper.

QUERO RODILES, F. (2009). Historia militar de la Primera Guerra Mundial. Madrid: Silex.

SANCHO GÓMEZ, M. P. (2003). "Blas de Lezo y Cartagena de Indias: una perspectiva desde el siglo XXI". En: Revista de la SEECI, n 10 , Madrid: Universidad Complutense, p. 75-94.

SASSOON, S. (2002). Memorias de un oficial de infantería. Madrid: Turner.

\section{Recursos electrónicos}

GILLHAM, S. (2000). Linea de fuego. El Somme 1916. The history channel: Cromwell Productions [22 de noviembre de 2005]

MARTIN, J. (2000). La Primera Guerra Mundial en color. Track Media [dvd]

\section{Notas}

1 Ambos bandos planificaron los movimientos que se desarrollarían en 1916 para obtener una victoria total. Pero lo que se consiguió fue alcanzar el cenit del periodo de desgaste, produciéndose dos de las batallas más sangrientas de la Primera Guerra Mundial, la batalla del Verdún y la batalla del Somme, que junto con la batalla de Jutlandia (contienda naval, en el mar del Norte, en el estrecho de Skagerrak) forman el tríptico más importante de este periodo.

2 Más allá de la controversia que Douglas Haig sigue levantando entre los historiadores por sus acciones en las batallas del Somme y de Passchendaele (1917, en realidad, la tercera batalla de Ypres), especialmente, es también destacable la supuesta campaña contraría al Mariscal de Campo John French que Haig habría orquestado para ocupar su puesto, empresa que se vio favorecida por la amistad que unía a éste con el monarca Jorge V.

3 Muy especialmente la del entonces ministro de Municiones, David Lloyd George, quien luego alcanzaría el cargo de Primer Ministro, contrario a Douglas Haig tras el desastre del Somme y a quien intentó destituir de su cargo, objetivo que no logró por los apoyos públicos que tan sólidamente había construido el Mariscal de Campo.

4 La formación de los británicos estaba compuesta por hombres procedentes también de Canadá, Terranova, Australia, Sudáfrica y Nueva Zelanda. En sus filas había soldados regulares que llevaban en acción desde el inicio de la contienda, soldados territoriales reclutados antes del conflicto, los veteranos de la batalla de Gallípoli (29a división, y el grueso formado por los nuevos hombres del renovado ejército, el ejército de Kitchener.

5 Como el mismo Haig explicó al Estado Mayor General británico, el avance se forzaría lo suficiente hacía el este para que la caballería se introdujese en campo abierto más allá de las líneas de defensa del enemigo. Esta incursión estaba destinada a ser la gran participación de la caballería en la Gran Guerra, abandonada después de la retirada de Mons en 1914.

6 Quero Rodiles. Op. cit., p. 315.

7 Veintiséis divisiones, unos 250.000 hombres.

8 Veintidós divisiones, 150.000 hombres.

9 Las agrupaciones de combate alemanas serían, más adelante, desdobladas: " 1 er ejército, del que tomaría el mando el general Von Below, con cinco divisiones; y $2^{\circ}$ ejército, al mando del general Von 
Gallwitz, con tres divisiones en primera línea, tres divisiones en segunda línea, y algunas divisiones más procedentes del sector de Verdún" (Quero Rodiles. Op. cit., p. 317).

${ }^{10}$ Unas 6.000 piezas de artillería y 6.000 .000 de proyectiles.

${ }^{11}$ Planteada como una batalla de desgaste del enemigo para que los alemanes redujeran la presión sobre el bastión francés de Verdún, es cierto, el Somme tuvo éxito, pese al alto coste de vidas humanas. Pero el avance fue insignificante y no se rompieron las líneas enemigas, aunque algunos protagonistas e historiadores interpreten que la victoria final de la Entente comenzó con el éxito de la batalla del Somme.

12 Una primera fase de ataque sobre la primera línea de la defensa alemana; una segunda fase de ataque sobe las segunda línea de las defensas enemigas; una tercera fase de conquista y ocupación de la línea Baupame-Peronne; y una cuarta fase protagonizada por la profundización hasta Cambrai.

${ }^{13}$ En la zona de Fricourt-Mametz.

${ }^{14}$ Inmortalizada para siempre por Geoffrey H. Molins y Ernest Brooks.

${ }^{15}$ Quero Rodiles. Op. cit., p. 326.

\section{El autor}

José Rodríguez Terceño es licenciado en Comunicación Audiovisual por la Universidad Complutense de Madrid y doctorando en la rama de cine de la misma institución. Miembro del Grupo de Investigación Validado Complutense Concilium, ha participado en diversas publicaciones colectivas centradas en la séptima arte, periodismo y las relaciones públicas. 